\title{
Discussion on the Reform of Teaching Methods of Mechanical Drawing
}

\author{
Qingran $\mathrm{Hu}$ \\ College of Mechanical Engineering, \\ Hubei University of Automotive Technology \\ Shiyan, Hubei, China
}

\begin{abstract}
Mechanical drawing mainly studies the use of engineering drawings to express spatial solids, which is the "language" used to exchange information in the engineering field. However, the course is difficult for beginners, and students tend to be weary of learning. Then how to inspire students' interest in learning and how to focus students' attention on the lecture are the problems that teachers need to think about urgently. At the same time, the previous teaching methods also need to be changed. First of all, teachers can encourage students to make their own teaching aids, which is more impressive than using existing teaching aids. Secondly, some chapters can reduce teaching time. Teachers assign tasks to students, and students get detailed information by themselves. After self-study, students will organize these materials into a report and submit it. The teachers verify the learning effect and give an evaluation. In the process of implementation, teachers should play a role of guidance and supervision. The purpose is to put students in the main position and make them participate more in the teaching process.
\end{abstract}

Keywords—change; interest; evaluation; supervision; participate

\section{INTRODUCTION}

Mechanical drawing is a basic course for students majoring in science and engineering, which is usually offered in the first year of University. This course is to study the use of plane graphics to express the shape, size and location of threedimensional space, etc. It has little connection with the knowledge of students in junior and senior high schools, and it can almost be treated as a new thing. Generally speaking, this course is a process of thinking from object to drawing and from drawing to object. The purpose of this course is not only to cultivate students' ability of drawing and reading engineering drawings, but also to train students' ability of spatial imagination. However, some students are not good at spatial imagination and study very hard. After the fresh feeling of contacting new things disappears, they begin to have no interest in the class and treat it negatively.

At present, the course is mainly made by teachers using three-dimensional software, animation, teaching aids and other means to enable students to understand the knowledge, and after class students do exercises to consolidate what they have learned[1]. The teachers are dominant, and the students passively accept the knowledge given by the teachers. There is interaction in the class but time is limited. In the course of teaching, once students can't keep up with the teachers' ideas,

Teaching research and reform project of Hubei University of Automotive Technology (JY2019021) their attention will be distracted, and it's hard to put them back into the class. After a few times, the enthusiasm for learning is obviously reduced. Students will play mobile phones or do other things unrelated to learning in class. In addition, the mechanical drawing requires students to have the ability of spatial imagination, but some students have the poor ability of it. Although there are three-dimensional software, animation, teaching aids to assist students in learning, the effect of these tools is not the same. The effect of teaching aids is good, but it can't be guaranteed that everyone has them. The others can be seen but not touched. It's also difficult for this part of students to understand, and the learning efficiency is very low. How to improve this situation, how to improve students' interest in learning, how to increase students' participation in the classroom, is an urgent problem to be solved.

\section{REFORM OF TEACHING METHODS}

\section{A. Making Teaching Aids}

First of all, in the teaching process, it is necessary to change the role of students, so that students can change from passive acceptance to active learning. Here are my personal views on the reform of teaching methods of mechanical drawing. According to the teaching order, students should first learn the projection of points, lines and planes, then the projection of solids and their intersections, composite solids, general principles of representation, detail drawings, commonly used parts and assembly drawings[2]. When students learn the projection of solids and their intersections, they begin to feel difficult. In class, teachers usually use threedimensional software to operate or show the models (as shown in Fig.1) to let students learn the drawing method of intersecting lines[3]. However, due to the problem of angle or short time, some students can't observe the real shape of intersecting lines, and they are shy or unwilling to go to the teacher to borrow the models to see again. In class, it is not effective to achieve the teaching objectives. The best way is that each student has a physical model to study. However, because the number of students is large and the number of models is small, the demand cannot be met. At this time, the teachers can divide the students into groups, arrange each group to sit together and distribute one of the models. Two classes should be set aside. Students use the plasticine to make the same shape according to the given model, and make teaching aids by themselves. After that, each group exchanges models until all types of models are made by themselves. At 
last, the teachers look at it and then give the evaluation as a usual result. With the help of plasticine, it deepens students' understanding of the shape of the intersecting lines, for example, intersection lines of cylinder: parallel intersecting plane with respect to the axis, the perpendicular intersecting plane with respect to the axis, the inclined intersecting plane with respect to the axis. In the second class, the teachers put forward the learning points in the lecture, and the students can learn by using self-made teaching aids. It is helpful for students to master the basic knowledge about how to draw intersecting lines, such as where are the special feature points, how to draw general points and complete the projection. Making teaching aids by hand can stimulate students' interest in learning. These models also can be saved and will continue to be used in subsequent chapters.
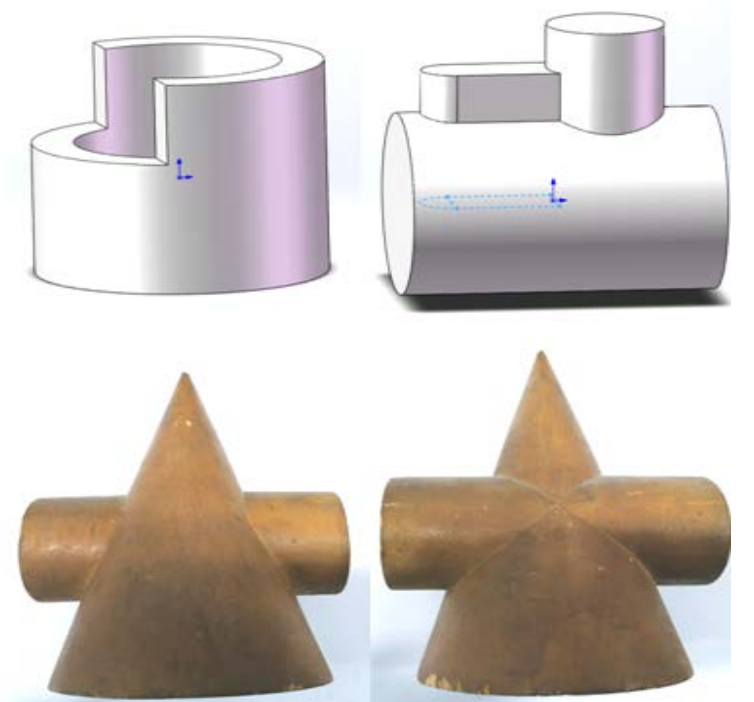

Fig. 1. Model display.

When learning composite solids, in order to improve students' ability of drawing three views, students can be divided into groups. Each group is given multiple composite solid models (the composite solid models constructed through superposition, cutting and hybrid construction, as shown in Fig. 2). Each group discusses how to draw three views of these models: shape analysis, selection of the front view, select the scale, draw the datum lines of each view, draw the three views, check and draw with regular lines. Then each student submits a drawing including three views of all models[4]. Before the drawing is submitted, each group should check internally, find out the mistakes and correct them in time. In order to play an incentive role, the group members will be given the same score after comprehensive evaluation. When learning the configuration of the composite solids, the plasticine used in the learning of the basic solids can be used again. The teachers put forward some restrictions, and students can use their spatial imagination to make composite solids of various shapes with plasticine as required. Every solid is checked whether it is correct by other students and the teachers. And it is helpful to increase students' interest in the lecture. Students should lay a good foundation for the composite solid to prepare for the learning of expression methods of the parts.
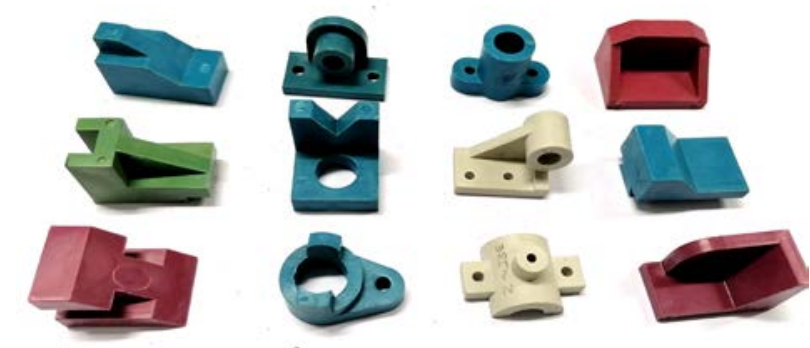

Fig. 2. Composite solids.

\section{B. Making Reports}

Before learning detail drawings, commonly used parts and assembly drawings, the teachers should reserve two hours of disassembly exercises. Some common components that teachers assign to students are shown in Fig. 3. According to the previous grouping method, each component of a group is disassembled at first. "How many kinds of parts are counted (shown in Fig. 4)? Are there any standard parts? How to express the parts to be expressed?" After the discussion, the group members determine the representations and draw a sketch of each part. Next, when the teachers teach the expression methods of the four typical parts in the lecture, the students can compare the sketches they have made, and directly communicate with the teachers and other students. It is easier to find problems and solve problems, and give full play to the main role of students. Then in the section of manufacturing processes and machining structures of parts, teachers can carry out heuristic teaching and guide students to find out whether there is any difference between each part in the component and the previous solids[5], pointing out the relevant manufacturing processes (casting structure and common machining structures) and technical requirements (surface texture, limits and fits, geometrical tolerances, heat treatment and surface treatments). Due to the limitation of class time, it is difficult for the teachers to explain these contents clearly in class. The teachers can regroup the students or use the previous groups. Next, students in each group can acquire relevant knowledge through textbooks, Internet or library collections after class, and finally, give a specific report in the form of a group. The teachers organize the reply in the classroom. The teachers and the group leaders serve as judges and judge the scores. In the process, the teachers also record the problems that the students have, and solve them in time. In order to prevent some students from being lazy, the teachers should communicate with the group leaders, knowing the specific generation process of the report, mastering which part which student is responsible for, whether they all know relevant knowledge, whether they all have searched for information and how many times they have communicated, which can not only help students acquire knowledge, but also help teachers understand the learning attitude of each student, so as to focus on some students with poor level. Care for the students through communication, counseling or other means, so that every student does not fall behind.

For the chapter of standard parts and common parts, please refer to the teaching methods in the chapter of parts drawing. The teachers arrange tasks and the students study in groups. 
Students access the data to understand the structure, use, symbol, mark, etc., focusing on the standardized drawing of standard parts and common parts. Then students make information into a PPT, and each member is familiar with the content. Next, change the identity from the student to the teacher. Students first try within the group (the process is recorded in video or written materials, and the materials are submitted), and the best students in the group are selected to compete with the students selected by other groups. The teacher and all students are judges, $90 \%$ for the students, $10 \%$ for the teachers, and the winners are selected. Teachers should give the group rewards, for example, the scores of the students in the group are higher than those of the other groups.
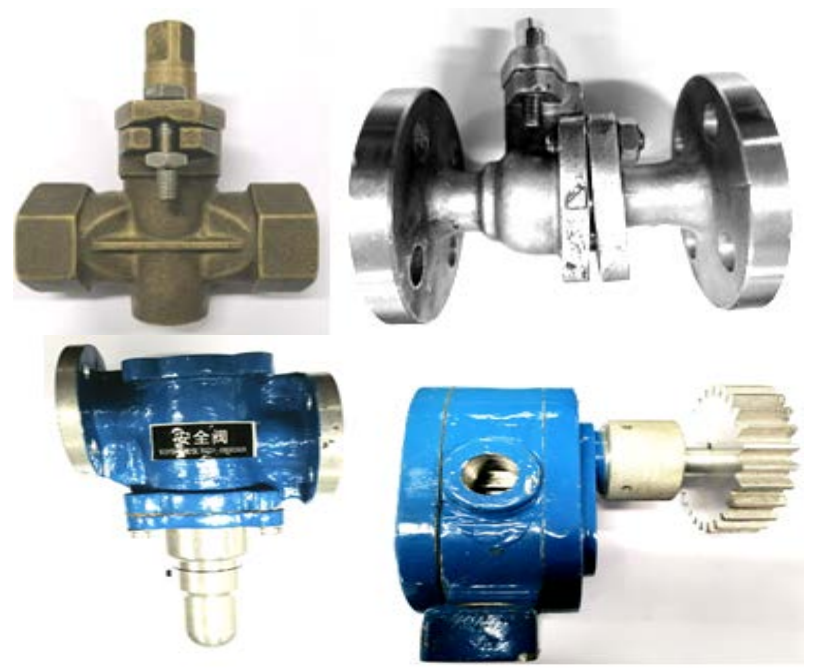

Fig. 3. Components
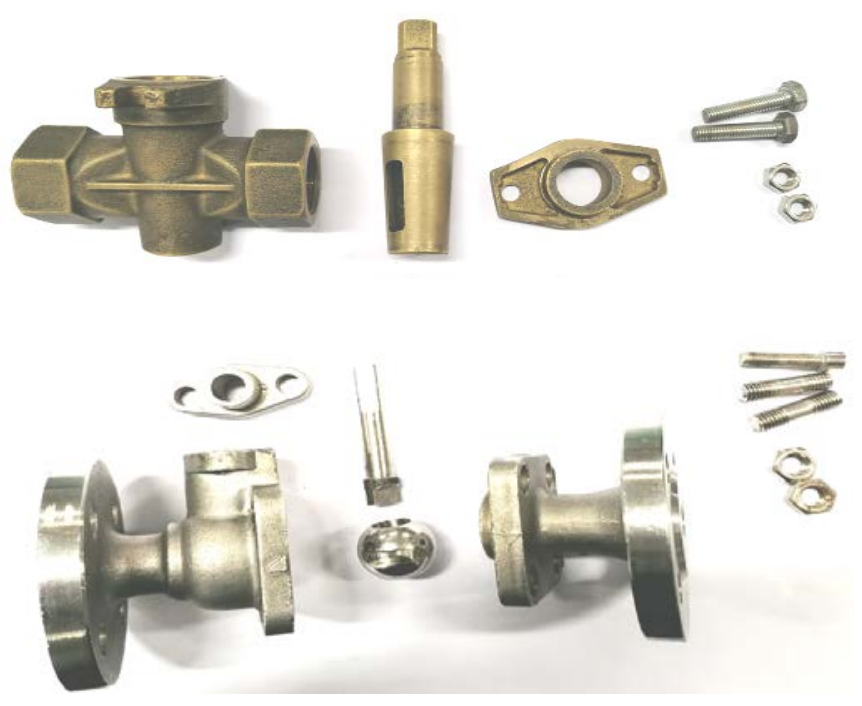

Fig. 4. Parts

Of course, with the development of technology, various application software is constantly appearing, and some of them are suitable for teaching. Teachers can use it to check attendance and interact with students[6]. Although the methods are diverse, teachers must do their best to get good results. Although it is important to highlight the status of students in the classroom, it is not to reduce the responsibility of teachers. On the contrary, teachers have to spend more time and energy than traditional teaching[7]. Because the ultimate goal is to encourage students to inspire their interest, and let them be willing to participate in teaching, so as to master graphics knowledge.

\section{CONCLUSION}

Mechanical drawing is a professional basic course, which is very important to lay the foundation for the follow-up courses. In the teaching process, it is necessary to change the status of teachers and students, that is, from the form of fullscale irrigation to the way of students actively acquiring knowledge. If the teachers give the students a ready-made thing, the students have an impression at first, but the memory is very short, and it is still strange to meet again, so it is necessary to rely on the students to participate. The teachers should try to increase students' participation in various ways, which can inspire students' learning interest, ensure students' predominant status in the class, create an interactive class atmosphere. At the same time, students who spend their time and energy on their own will bring them a sense of accomplishment, and the relevant knowledge involved will be very impressive. It is better than passive acceptance. In order to enhance the practical effect, it is recommended not to carry out the above activities for a single student. It is better to take the form of grouping. Each activity should be evaluated and the scores of group members are the same. In this way, students can supervise each other and improve their communication. Teachers play a guiding and supervisory role in the practice process, keeping communication with students, understanding students' dynamics, finding out problems and solving them in time.

\section{REFERENCES}

[1] Keqin Jiang, Wei Zhang, "Discussion on the inspiring measures of learning initiative in mechanical drawing teaching," Hubei Agricultural Mechanization, 2019, pp.95-96.(In Chinese)

[2] Lin Hu, Rong Cheng, Qin Fu, Wei Sun, Fenghong Wang, Xiaobo Peng and Mingli Zhang, Engineering Drawing(English-Chinese Bilingual Edition), 2nd ed., Beijing: China Machine Press, 2010.

[3] Hao Wan, Zhan Ding, Jian Wang, Zhenjiang Zhao, et al., "Discussion on the application of Solid Works in the course of descriptive geometry and mechanical drawing,” Education Modernization, 2019, pp.186-188.(In Chinese)

[4] Yongfeng Guo, "Research on the cultivation method of mechanical drawing space imagination ability," China Southern Agricultural Machinery, 2019, p.204.(In Chinese)

[5] Wei Xie, Yiyi Zhao, "Talking about the role of teacher in guiding text teaching method in mechanical drawing application,” Talent Resource Development, 2016, p.194.(In Chinese)

[6] Juan Cheng, YuLin Wang, Dian Tjondronegoro, and Wei Song, "Construction of interactive teaching system for course of mechanical drawing based on mobile augmented reality technology[J]”, International Journal of Emerging Technologies in Learning, 2018, 13(02), pp.126-139.

[7] Lu Xiao, Jing Wang and Xiangman Zhou, "Student participation research based on SPOC-based mixed teaching model," University Education, 2019, pp.76-78.(In Chinese) 